\title{
The effects of organization context on knowledge exploration and exploitation
}

\author{
Rodrigo Valio Dominguez Gonzalez ${ }^{\mathrm{a}, *}$, Tatiana Massaroli de Melo ${ }^{\mathrm{b}}$ \\ a School of Applied Science, University of Campinas, Rua Pedro Zaccaria, 1300, 13484-350 Limeira, São Paulo, Brazil \\ b Department of Economics, Paulista State University Julio de Mesquita Filho (UNESP), Araraquara, Brazil
}

\section{A R T I C L E I N F O}

\section{Keywords:}

Knowledge exploration and exploitation

Innovation

Learning culture

Leadership

Human resource management

Autonomy

\begin{abstract}
A B S T R A C T
The knowledge-based view of the firm points knowledge as the main resource able of generating competitive advantage for organization. This competitive advantage is the result of the innovative process, which requires knowledge exploration and exploitation. Several studies have aimed to analyze factors that support the knowledge management (KM) process and generate taxonomies related to the practice of KM. However, there is a gap in the literature on organizational knowledge regarding the relationship of contextual factors with the knowledge exploration and exploitation process as well as with the generating of a typology that considers these two processes. To achieve this goal, this study uses a quantitative approach, based on a survey with 234 companies in the automotive industry. Our results show that the knowledge exploration and exploitation process are differently impacted by five contextual factors considered in this research - human resources management, supportive leadership, learning culture, autonomy and systems of information technology (IT). While exploration is more impacted by learning culture, autonomy and IT systems, exploitation is more associated with supportive leadership and learning culture. Considering innovation for knowledge exploration and exploitation and contextual factors, this research also identifies three clusters in the automotive industry, named innovative companies, exploitative companies and passive companies.
\end{abstract}

\section{Introduction}

The intensity of business competition has significantly increased and the knowledge is the main organizational resource able to generate a competitive advantage through innovation (Grant, 1996; Torugsa \& O'Donohue, 2016). In this context, knowledge management (KM) has become one of the most influential models in the field of Managerial Sciences. Recent surveys show that KM influences the performance of firms as it offers an effective framework for implementing innovation strategies (Lee, To, \& Ty, 2013; Lin, 2014). KM applications are not restricted to the business world. Blanco, Echaluce, and Peñalvo (2015), for example, have developed a model of ontological spirals for innovation in higher education. The authors propose that the individuals' knowledge is transferred to the universities in order to reach educational innovations.

Much of the research on KM seeks to relate the knowledge creation, storage, distribution and application to organizational performance, in terms of financial results and innovative performance (Chen, Huang, \& Siao, 2010; Jones \& Knoppen, 2018; Lee et al., 2013). It is noted in the literature that little attention has been given to the impact of the contextual factors of the organization that support the firm's KM process and innovation. Some studies examine the influence of one factor in isolation in relation to KM and innovation, as occurs in Martins and Meyer (2012) and Zangiski, Lima, and Costa (2013), who focus on the relationship between human resources and KM; Corfield and Paton (2016) and Marouf (2016), who deal with the relationship between organizational culture and KM; and Gonzalez, Martins, and Toledo (2014), Chen et al. (2010) and Chen and Huang (2007), who focus on the relationship between organizational structure and KM; and also Kane and Alavi (2007) who relate Information Technology (IT) systems and KM. However, White and Cicmil (2016) warn that it is essential to treat these factors simultaneously, for analyzing a single factor in isolation can lead to erroneous conclusions.

The literature addresses the factors related to $\mathrm{KM}$ as "organizational contextual factors" (Gonzalez \& Martins, 2014; Martins \& Meyer, 2012; White \& Cicmil, 2016) or "success critical factors of KM" (Gold, Malhotra, \& Segars, 2001; Lee \& Choi, 2003; Lin, 2014). In this study, the first terminology is used. These factors establish the organizational behavior, in what concerns values and beliefs that guide individuals, integration and forms of organization of employees into groups, level of

\footnotetext{
* Corresponding author.

E-mail addresses: rodrigo.gonzalez@fca.unicamp.br (R.V.D. Gonzalez), tmassaroli@fclar.unesp.br (T.M. de Melo).
} 
training of employees, and the posture assumed by the company's management. Without the effort to develop these factors, any organizational initiatives geared towards KM ends up not creating the expected benefits (Gonzalez \& Martins, 2014).

Considering that contextual factors are developed differently by organizations and that its impact the ability to knowledge exploration and exploitation, the innovative capacity will also be affected by the development of these factors (Gonzalez \& Melo, 2017; Patterson \& Ambrosini, 2015; Gonzalez et al., 2014; Chen et al., 2010; Torugsa et al., 2016). In this sense, the main objective of this study is to analyze how five factors of the organizational context (Human Resource Management, Supportive Leadership, Learning Culture, Autonomy and Information Technology system) are related to the processes of innovation from knowledge exploration and exploitation in automotive industry. In addition, this study presents a secondary objective, the development of a typology of companies in the automotive industry that considers the level of innovation through knowledge exploration and exploitation and also of the contextual factors of the organization.

\section{Knowledge exploration and exploitation}

Innovative process is crucial for companies to create strategic flexibility and maintain competitive advantage. Many studies classify innovation from the way knowledge is applied, accessed, and rescued (Gonzalez, 2017; Lee, Park, \& Kang, 2018). Previous studies classify innovation as explorative or exploitative depending on the proximity to technologies, products, services and consolidated processes (Lee et al., 2018; March, 1991). Exploratory innovation is developed to search and acquire unfamiliar and novel technologies and resources and aims to generate variation. Exploratory includes things captured by terms such as search, variation, risk taking, experimentation and flexibility (March, 1991). The level of primary knowledge will restrict the acquisition of new knowledge that supports the process of innovation through exploration (Grant, 1996). Otherwise, exploitative innovation is conducted to meet the needs of customers and current markets, expanding the existing products and services, and also refining and improving the efficiency of the processes. In comparison with exploratory innovation, exploitative innovation is based on knowledge and information associated with primary knowledge and skills.

The establishment of the concept of knowledge exploration and exploitation has led to research on ambidexterity strategy, in which firms pursue both short-term survival and long-term growth by combining these two organizational learning activities (Lee et al., 2018; He \& Wong, 2004). March (1991) emphasizes that the results associated with exploration are more variable and long-term, while the results relating to exploitation are more precise and short-term. In other words, companies that exploit new knowledge generate great variation in performance, while the use of exploitation leads to a more stable performance. Levinthal and March (1993) and Ganzaroli, Noni, Orsi, and Belussi (2016) argue that it is important for companies to maintain an appropriate balance between exploration and exploitation to increase competitiveness.

Exploration and exploitation require significantly different structures, processes, strategies, capacity, and culture. In general, exploration is associated with an organic structure, systems that are not rigid, improvisation, and autonomy. Exploitation, on the other hand, is associated with mechanical structures, more rigid systems, routine, control, and bureaucracy (Holmqvist, 2004).

To achieve the organizational ambidexterity firms need to balance innovation by knowledge exploration and exploitation (Hill \& Birkinshaw, 2014). March (1991) consider that there is tension between exploration and exploitation. If on the one hand, adaptation to the environment can promote inertia, in addition to reduction of the company's capacity to adapt to new opportunities, on the other, trying new alternatives reduces the speed at which the existing competences are improved and refined (March, 1991).
Ganzaroli et al. (2016) and Gupta, Smith, and Shalley (2006), argue that an excessive focus on exploitation results in organizational "shortsightedness," hindering innovation and leading to a process of obsolescence. Similarly, excessive exploitation is also equally destructive, because organizations can enter into a cycle of failure - research change - failure. The authors argue that based on the failures, polls are originated in the organizations, which support the changes that, in turn, will result in new failures, initiating a new cycle of research. These organizations suffer from never gaining the return of their acquired knowledge. Crossan and Bedrow (2003) believe that there are important implications in balancing exploitation and exploration. According to the author, the organizations that manage knowledge well are competent in developing innovative ideas, as well as in institutionalizing and redeeming individual learning.

There is a complementary effect between the two strategies: exploitation promotes static optimization, while exploration supports dynamic optimization. The success of a company when competing in stable environments involves the exploitation of the consolidated competences, while surviving in dynamic environments involves the development of new competences. Thus, the two strategies are essential to maintain a competitive edge, and their combination is implied in recent concepts that deal with the organization's dynamic capabilities (Eisenhardt \& Martin, 2000).

\section{Contextual factors that support KM}

The knowledge-based view of the firm proposes that knowledge generation, retention, distribution and application process are the firm's core activities (Grant, 1996). This theory places knowledge to be the main strategic resource because it enables the company to create cultural, intellectual, social and economic value (Zack, McKeen, \& Singh, 2009). In this context, the firm is an entity that is continuously transforming its acquired knowledge through its dynamic capabilities, in a prospect of knowledge exploration and exploitation (Kogut \& Zander, 1992).

Grant (1996) recognizes two types of contributions from KM. The first refers to the recognition of two kinds of knowledge - tacit and explicit knowledge - that require different approaches for their management. While explicit knowledge is presented in codified form; tacit knowledge is manifested through abilities and skills intrinsic to people (Zack et al., 2009). The second contribution concerns the way in which the knowledge is renewed or transformed. Grant (1996) proposes that organizations can transform knowledge into a continuum between exploitation, that is, using the same primary knowledge base in order to achieve incremental improvements; and exploration, which focuses on research, discovery and experimentation in order to modify the primary knowledge acquired (March, 1991).

Two contributions enunciated by Grant propose that KM should be addressed as a social and technical phenomenon (Lin, 2007; Van Dijk, Hendriks, \& Romo-Leroux, 2016). In this sense, the KM process is conditioned by organizational development. This organizational development that supports KM is associated with contextual factors and IT systems act as support mechanisms related to the processing, retention and distribution of explicit knowledge through integrative applications such as knowledge repositories (Zack et al., 2009), as well as promoting the exchange of tacit knowledge among individuals through interactive applications such as discussion forums (Park, Stylianou, Subramaniam, \& Niu, 2015).

Organizational culture is a contextual factor often listed by scholars (Chen \& Huang, 2007; Corfield \& Paton, 2016; Gonzalez \& Martins, 2014; Gonzalez \& Melo, 2017; Lin, 2014; Marouf, 2016). The success of KM depends on the integration of strategy and vision with organizational culture and structure to promote the exchange of knowledge, experimentation, appropriate degree of autonomy and leadership support, and also the motivation and development of employees who retain the primary knowledge (Gold et al., 2001). Heisig (2009) identified four 
categories related to contextual factors that support KM: factors related to people, which include learning culture, human resource development and leadership; factors related to the organization, concerning the organizational structure; factors related to management processes, with regard to the organizational strategy; and factors related to technology, which concern the IT systems.

In further discussing the identification of these critical factors, we assessed the proposals of some authors. Chourides, Longbottom, and Murphy (2003), highlight the factors related to organizational strategy, human resource management (HRM) and IT. Davenport, De Long, and Beers (1998) conducted an exploratory study in 24 companies and established eight critical factors for KM: economic performance, clear language, flexible organizational structure, multiple channels for knowledge transfer, "friendly" culture, technical infrastructure, motivational and support management practices. Gonzalez and Martins (2014), based on a survey in companies in the automotive industry, identified eight critical factors: HRM, proactive leadership, learning culture, lean organizational structure, teamwork, primary knowledge, IT, incremental improvement and innovative strategy. Lin (2014) divides the contextual factors that support KM into two groups. The first, named technological context, includes the support of IT systems; and the second, named organizational context, consists of managerial support, learning culture and awards system. And, finally, the APQC (2003) establishes four critical factors for KM: leadership, learning culture, strategy and technology. In this way, based on Heisig's (2009) contribution and above-mentioned factors, this study considers the following contextual factors that support KM:

- Those related to people: HRM and supportive leadership;

- Those related to organization: organizational learning culture and autonomy;

- Those related to technology: IT systems.

\subsection{Human resource management}

The most recent research on human resources management proposes that the level of excellence of organizational competences is a reflection of the training and education of the employees (Zangiski et al., 2013). KM initiatives depend on the willingness of people to share their knowledge and skills. No organization can generate knowledge without qualified employees (Figueiredo, Pais, Monteiro, \& Mónico, 2016; Zangiski et al., 2013). Team members are the central element of the knowledge generation and application process. Organizations should create mechanisms to develop and stimulate these processes (Figueiredo et al., 2016). In this context, HRM faces new and complex challenges. A HRM that supports knowledge creation and use aiming at innovation cannot feature traditional and eminently bureaucratic and mechanistic characteristics, but be guided by functions (Bontis \& Serenko, 2007; Dominguez, 2011). HRM is understood in this study as the set of policies, systems, and practices that influence the behavior, attitudes, and performance of the team members to increase their learning capabilities, creating a learning-oriented culture (Razouk, Bayad, \& Wannenmacher, 2009). The contemporary vision proposes that HRM should play roles that contribute to greater flexibility and greater organizational adaptability. These considerations give way to the first set of hypotheses:

H1. a. HRM is positively related to innovation through knowledge exploration. b. HRM is positively related to innovation through knowledge exploitation.

\subsection{Supportive leadership}

KM combines technological and social activities performed by individuals that make up the organization, who create, store, share and utilize knowledge in order to achieve innovation and performance improvement. Leadership, in turn, plays a vital role of motivating, influencing and guiding individuals in that direction. Politis (2001) examined the relationship between transformational and transactional leadership, self-management, and several attributes of KM. Politis identified that these three leadership styles are related to the process of knowledge acquisition. He highlights the need for managers to promote the development of an organizational environment focused on the autonomy of individuals and groups. Politis' research results are aligned with other research such as those by Donate and Guadamillas (2011) and Analoui, Doloriert, and Sambrook (2012), who highlight the need for participatory and supportive leadership in order to support the creative and innovative process within the organization. The role of supportive leadership is based on encouraging the members of the firm and the voluntary application of individual talents aiming at the creation of new knowledge that generate a competitive edge (Donate \& Guadamillas, 2011). Leaders should, therefore, encourage experimentation and facilitate the sharing of knowledge through the granting of autonomy, making use of guidance and confidence. Lakshman (2007) suggests that the perception of the leader about the importance of KM needs to manifest itself along two dimensions, one internal and one external. Internally, the understanding of the leader on the importance of $\mathrm{KM}$ is critical to the establishment of technological procedures and initiatives, focused on IT systems, and cognitive and social initiatives, which support activities of innovation and performance improvement. This theoretical discussion gives way to the second set of hypotheses:

H2. a. Supportive leadership is positively related to innovation through knowledge exploration. b. Supportive leadership is positively related to innovation through knowledge exploitation.

\subsection{Learning culture}

Organizational culture can be defined as a set of values that governs the attitudes of individuals on how to act and propose changes and innovations (Naqshbandi \& Tabche, 2018). It not only reflects the values that influence employee behavior, but is deeply embedded in employees' actions and their mutual expectations, influencing how employees interact and how decisions are made (Islam, Khan, Ahmad, Ali, \& Ahmed, 2014). Organizational culture is a critical factor in the development of an environment that encourages the reconfiguration and renewal of core competencies (Corfield \& Paton, 2016). According to Islam et al. (2014), the learning culture helps an organization continually seek new knowledge, apply it in routines, reconfiguring its skills and improving innovative performance.

However, developing a culture that promotes the learning and $\mathrm{KM}$ is still a major challenge for organizations (Islam et al., 2014; Naqshbandi \& Tabche, 2018). Although learning is considered critical for organizational success, the difficulties encountered in this process highlight the necessary changes in mental and cognitive structure of an organization's members (Corfield \& Paton, 2016; Donate \& Guadamillas, 2011).

Organizational learning culture proposes that the interests of the group and collective good take precedence over individual interests (Zheng, Yang, \& McLean, 2010). As a result, it is natural to assume that in environments where culture is supportive, individuals are more willing to share their knowledge with the other team members, intensifying the flow of knowledge (Li, 2010; Ma, Huang, Wu, Dong, \& Qi, 2014). This discussion gives way to the third set of hypotheses:

H3. a. Learning culture is positively related to innovation through knowledge exploration. b. Learning culture is positively related to innovation through knowledge exploitation.

\subsection{Autonomy}

An organization with highly centralized structure requires that 


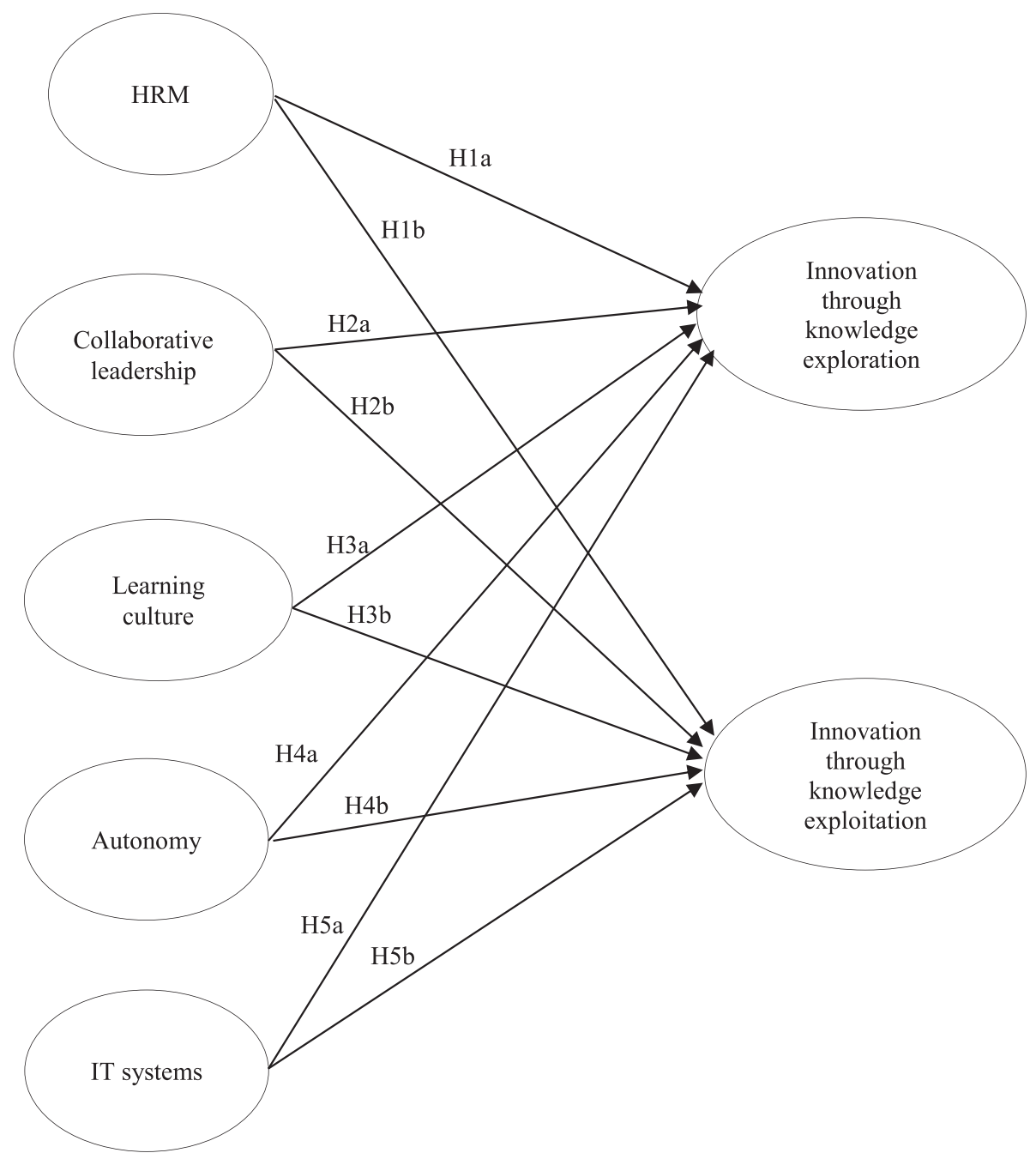

Fig. 1. Research model.

employees comply with guidance originated from a specific channel (Ho, Hsieh, \& Hung, 2014). However, this structural model slows down decision-making and restricts the flow of internal information and knowledge, suppressing the creative and innovation process (Lee \& Choi, 2003). On the contrary, a decentralized organizational structure, which gives autonomy to employees, disperses authority to individuals and groups, offering opportunities to promote the creation and sharing of ideas, supporting the creation and transformation of knowledge (Lee \& Choi, 2003).

Autonomy can be defined, therefore, as the amount of interdependence, initiative and freedom granted to employees for daily work-related decision making and executing (Chen \& Huang, 2007). Autonomy gives employees individual freedom for seeking solutions to problems or for self-organizing networks of social interaction to solve these problems or even for planning and implementing improvements. Autonomy is the basis of self-organization and increases the likelihood of individuals becoming motivated to learn continuously through the creation of new knowledge and competences (Chen et al., 2010; Gonzalez et al., 2014). When the degree of autonomy is increased, managers do not specify targets, allocation of staff or lines of authority. This implies that employees start feeling more responsible for their own work and process. The organization thus encourages the creation of new ideas and knowledge, generating a more innovative context (Chen et al., 2010; Ho et al., 2014). This theoretical discussion gives way to the fourth set of hypotheses:
H4. a. Autonomy is positively related to innovation through knowledge exploration. b. Autonomy is positively related to innovation through knowledge exploitation.

\subsection{IT systems}

One of the main challenges in the field of KM resides in analyzing the contribution of IT systems and tools in relation to the firm's innovative performance and activity. Previous studies indicate that IT alone is unable to give a competitive edge and its effective use within the organizational context depends on its association with the development of other factors, in particular, those cited previously in this study (Donate \& Guadamillas, 2011; Mohamed, Stankosky, \& Murray, 2006; Xue, Bradley, \& Liang, 2011).

In relation to the increased flow of information and knowledge in the organization, it is important to stress the role of the IT systems. Organizations, divided into departments, units and branches, rely on an IT system that stores, formalizes and distributes explicit knowledge (Xue et al., 2011). Thus, this research considers that IT systems are facilitators of the KM process, it being up to individuals the action itself so that this stored and distributed knowledge assigns value to the organization.

Bansler and Havn (2004) highlight that tools such as Data Warehousing and Data Mining accelerate the learning process, support the autonomy of employees, enable teamwork as well as access to 
information and knowledge. Therefore, this type of tool is capable of storing the best organizational practices (Gonzalez \& Martins, 2014) and processing multiple combinations of analyses.

Other tools such as the internet, the intranet, groupwares, video conferences, among others, increase the opportunities for people to meet and develop new knowledge, breaking the traditional barriers generated by departmental 'barriers', arising from the organizational structure (Mohamed et al., 2006).

Bansler and Havn (2004) point out that success in the application of these technologies depends on the expansion of the repository of knowledge and on the improvement of individual skills, for expanding the knowledge base of the organization is only made possible through the training of employees. In addition, a wide opening of the company's knowledge base depends on employees who are able to interpret this knowledge, as well as to apply it in situations that generate an increase in performance. Gonzalez and Martins (2014) and Xue et al. (2011) add to this discussion by explaining that it is up to professional experts knowing how to analyze, select and define what information are useful for, otherwise, the knowledge base becomes a mass of data and information with little value to the organization. This theoretical discussion gives way to the fifth set of hypotheses:

H5. a. IT systems are positively related to innovation through knowledge exploration. b. IT systems are positively related to innovation through knowledge exploitation.

Fig. 1 summarizes the model treated empirically in the next section. The Appendix identifies 18 items of measure, laid out based on the contextual factors, called exogenous or independent variables, and six measure items, laid out based on the practice of innovation through knowledge exploration and exploitation, known as endogenous or dependent variables.

\section{Research method}

\subsection{Data collection}

This study uses the collection of primary data in order to perform an empirical analysis that allows classifying the automobile industry's companies regarding the practice of KM and its implications in relation to innovation from knowledge exploitation and exploration. The research questionnaire was made up of two parts. The first deals with issues that characterize the company and the employee, and the second refers to the five constructs addressed in this research, as seen in the Appendix.

Initially, a pilot study was conducted with 12 professionals, graduated in the fields of Administration and Engineering, working in companies from the mechanic metal industry. They answered the initial questionnaire and provided comments during an individual meeting with the researcher via Skype. Based on the feedback from this step, the questionnaire was redesigned to improve its understanding and logical sequence, four questions were rewritten, one was removed, and two other were added.

The study was conducted in the Brazilian automotive industry. A total of 580 questionnaires were sent via email to management-level staff in the areas of production, human resources and engineering of companies registered in the National Association of Brazilian Auto Parts Manufacturers (SINDIPEÇAS), from September 2016 to December 2016. Along with the questionnaire, a letter of invitation was sent, in which the researcher elucidates the interest and importance of the survey. A total of $236(40.70 \%)$ questionnaires returned, of which 2 were excluded due to problems with how they were filled. Therefore, the survey covered a total of 234 valid questionnaires, representing a return rate of $40.34 \%$.

\subsection{Measures}

The measure variables or items of the contextual factors studied (Appendix) are calculated based on a six-point Likert scale, where 1 means "never practiced or total disagreement" and 6 means "always practiced or total agreement." The measure of Cronbach's alpha is used to estimate the reliability of the measure items. As shown below, all items showed an acceptable level of reliability, since $\alpha$ exceeded the value of 0.7 (Hair, Hult, Ringle, \& Sarstedt, 2013). The development of the measure items was based on the following studies:

- HRM ( $\alpha=0.873)$ : measurement items adapted from the work of Figueiredo et al. (2016) and Bontis \& Serenko, 2007;

- Supportive leadership ( $\alpha=0.841)$ : measurement items adapted from the work of Donate and Guadamillas (2011);

- Learning Culture ( $\alpha=0.885$ ): measurement items adapted from the work of Ma et al., 2014;

- Autonomy $(\alpha=0.770)$ : measurement items adapted from the work of Lee and Choi (2003);

- IT systems ( $\alpha=0.793)$ : measurement items adapted from the work of Xue et al. (2011);

- Practices of knowledge exploration ( $\alpha=0.766)$ : measurement items adapted from the work of Donate and Guadamillas (2011);

- Practices of knowledge exploitation $(\alpha=0.812)$ : measurement items adapted from the work of Donate and Guadamillas (2011).

\subsection{Data analysis}

The modeling of the structural equation based on the LISREL model is well-known and widespread. However, this procedure is not wellsuited to treat smaller samples, as in the case of this survey (Hair et al., 2013). In order to avoid some limitations of the LISREL model, an alternative is the causal modeling technique based on partial least squares (PLS). In contrast to the LISREL model, the management field, including studies in the area of organizational learning, intellectual capital and knowledge management, offers adherence and good results based on the PLS technique (Hair et al., 2013).

According to Hair et al. (2013), the process of defining of the model starts based on the theoretical framework on the subject. Next, three evaluations that are relevant to the application of the PLS technique in the context of management research should be considered: the evaluation of the measures of reliability and convergent and discriminant validity, the determination of the relationship between the items (variables) and constructs, and finally, the interpreting of the path coefficients and general suitability of the model.

Initially, the reliability and convergent and discriminant validity of the factors was analyzed through confirmatory factor analysis (CFA). The values of construct reliability (CR) $>0.70$ and Cronbach's $\alpha$ above 0.70 indicate that the constructs have acceptable levels of reliability. A $\mathrm{CR}>0.70$ and the factorial charges of the measure items having values above 0.50 in what concerns their respective factor points to the existence of convergent validity (Hair et al., 2013). Discriminant validity is verified through the average variance extracted (AVE). When the AVE values of the factors are $>0.50$, the discriminant validity is accepted (Hair et al., 2013). In addition, the discriminant validity is also verified through the matrix that shows the AVE's square root and the correlations between the factors. When the square root of a particular factor's AVE is higher than the other correlations, discriminant validity is verified (Hair et al., 2013). SmartPLS version 3.0 was used to evaluate the measures and structural model of this research.

To supplement the structural model, the procedure of cluster analysis was used to investigate the possible existence of dominant standards for the development of the organization's contextual factors.

The cluster analysis conducted in this research aims to develop a typology based on empirical data, identifying similarities between the cases regarding the variables raised theoretically and, consequently, 
Table 1

Reliability and convergent validity.

\begin{tabular}{|c|c|c|c|c|}
\hline Factor & Item & Factor loading & $\mathrm{CR}$ & AVE \\
\hline \multirow[t]{5}{*}{ HRM } & HRM1 & 0.811 & 0.818 & 0.733 \\
\hline & HRM2 & 0.735 & & \\
\hline & HRM3 & 0.793 & & \\
\hline & HRM4 & 0.856 & & \\
\hline & HRM5 & 0.837 & & \\
\hline \multirow[t]{3}{*}{ Supportive leadership (SL) } & SL1 & 0.745 & 0.765 & 0.708 \\
\hline & SL2 & 0.780 & & \\
\hline & SL3 & 0.733 & & \\
\hline \multirow[t]{4}{*}{ Learning culture (LC) } & LC1 & 0.818 & 0.823 & 0.756 \\
\hline & LC2 & 0.844 & & \\
\hline & LC3 & 0.863 & & \\
\hline & LC4 & 0.771 & & \\
\hline \multirow[t]{3}{*}{ Autonomy (Aut) } & Aut1 & 0.749 & 0.750 & 0.680 \\
\hline & Aut2 & 0.784 & & \\
\hline & Aut3 & 0.832 & & \\
\hline \multirow[t]{3}{*}{ IT systems (IT) } & IT1 & 0.820 & 0.783 & 0.688 \\
\hline & IT2 & 0.754 & & \\
\hline & IT3 & 0.776 & & \\
\hline \multirow[t]{3}{*}{ Knowledge exploration practices (Expl) } & Expl1 & 0.766 & 0.771 & 0.673 \\
\hline & Expl2 & 0.815 & & \\
\hline & Expl3 & 0.785 & & \\
\hline \multirow[t]{3}{*}{ Knowledge exploitation practices (Expt) } & Expt1 & 0.728 & 0.738 & 0.615 \\
\hline & Expt2 & 0.765 & & \\
\hline & Expt2 & 0.792 & & \\
\hline
\end{tabular}

simplifying the cases' analysis through the cluster. The typology analyzed in this study consists in the classification of company clusters, considering the practice of innovation through exploitation and the development of the organization's contextual factors in the surveyed companies of the automotive industry. The SPSS 21.0 software was used to perform the cluster analysis.

\section{Results}

\subsection{Convergent and discriminant validity}

To assess the reliability of the factors, this study uses the Cronbach's alpha and construct reliability (CR) measures. All Cronbach's alpha values were acceptable, i.e., $>0.70$, as indicated in the previous section. The values of CR and factor loading are shown in Table 1 . The CR values of the constructs are $>0.70$, indicating convergent validity, i.e., the variables that constitute the constructs display common variance. In addition, the factor loading of the items over their constructs is $>0.60$ and the AVE values are $>0.50$.

The average variance extracted values (AVE) of the constructs points to the existence of discriminant validity, i.e., the constructs are distinct from each other. In Table 2, the off-diagonal values correspond to correlations between constructs, and the diagonal refers to the square root of the AVE values of each construct. It is possible to notice that the square root values of the AVEs for each construct are greater than the correlation with the other constructs, indicating the existence of discriminant validity.

Table 2

Discriminant validity.

\begin{tabular}{llllllll}
\hline Factor & HRM & SL & LC & Aut & IT & Expl & Expt \\
\hline HRM & 0.856 & & & & & & \\
SL & 0.165 & 0.841 & & & & & \\
LC & 0.183 & 0.318 & 0.869 & & & & \\
Aut & 0.156 & 0.336 & 0.246 & 0.846 & & & \\
IT & 0.121 & 0.084 & 0.127 & 0.075 & 0.829 & & \\
Expl & 0.188 & 0.144 & 0.180 & 0.263 & 0.147 & 0.820 & \\
Expt & 0.175 & 0.163 & 0.193 & 0.215 & 0.249 & 0.331 & 0.784 \\
\hline
\end{tabular}

Observation: The elements of the diagonal cells refer to the square root of AVE.

\subsection{Structural model}

The Goodness of Fit (GoF) index and $\mathrm{R}^{2}$ measure of the endogenous (dependent) variables validate the PLS model, evaluating the consistency of the measures and of the structural model. GoF is used to determine the global prevision power of the model, considering the parameters of the measures scale and of the structure (Hair et al., 2013). The GoF found for this study's model is 0.38 , exceeding the cutting value of 0.290 for large $\mathrm{R}^{2}$ effects suggested by Hair et al. (2013), pointing out the great explanatory power of the model.

The path coefficients in the PLS model are similar to the $\beta$ coefficients of the regression analysis (Hair et al., 2013). Fig. 2 and Table 3 presents the results of the structural model. The $\mathrm{R}^{2}$ value was 0.387 and 0.425 for innovation through knowledge exploration and exploitation, respectively, suggesting that $38.7 \%$ of the variance of innovation through knowledge exploration and $42.5 \%$ of the variance of innovation through knowledge exploitation can be explained by the five contextual factors included in the study.

\subsection{Cluster analysis}

The cluster analysis aims to obtain a typology with common features and behaviors within the clusters for development of the contextual factors that underpin KM. Cluster analysis was performed using the SPSS 21.0 software. Prior to application of the cluster analysis technique, it is necessary to verify the adequacy of the sample data. To this end, the KMO test and Bartlett's sphericity test were used. The KMO statistic for each construct ranged between 0.725 and 0.884 , within the range recommended by Hair et al. (2013), showing the adequacy of the sample data. Bartlett's sphericity test also achieved statistical significance for all constructs $(p<0.001)$, rejecting the hypothesis that the measure items are an identity matrix.

The two-stage cluster analysis, which combines the hierarchical and non-hierarchical methods, was employed in this study. As for the hierarchical model, the method of minimum variance of Wards was used in order to establish the number of clusters. The procedure resulted in a solution with three clusters. Then, the non-hierarchical model K-means was applied to evaluate the robustness of the results of three clusters obtained previously through the hierarchical method. The k-means method resulted in a solution with three clusters with the following sample sizes: 15 (19.23\%), 52 (66.67\%) and 11 (14.10\%), respectively. Table 4 presents the results of the k-means cluster analysis. The results show that the average values of all the constructs are significantly different between the three clusters.

Table 5 presents the centroids of the three clusters, which represent the importance of each factor's measure in relation to the clusters obtained, on a six-point scale. An initial analysis of the characteristics of the clusters shows three variations concerning the innovation and development of the organization's contextual factors.

Cluster 1 ( $n=15,19.23 \%$ ) is named Innovative Companies, due to its high values with regard to the contextual factors and, in particular, in relation to the knowledge exploitation and exploration. Cluster 2 ( $n=52,66.67 \%$ ) is named Exploiting Companies, due to it standing out in relation to the innovation through exploitation factor, with average levels with regard to the other factors. Finally, Cluster 3 ( $n=11,14.10 \%$ ) is named Passive Companies, for having the lowest indexes of knowledge exploration and exploitation, and, in addition, this cluster's companies exhibit relatively low values with regard to the other factors surveyed.

Table 6 presents the descriptive characteristics of the clusters. In relation to the type of supplier, the study considers two types: nonstrategic and strategic. Strategic suppliers are those who participate in the process of designing the product, that is, in addition to being part of the manufacturers' supply chain, these suppliers develop parts of the vehicles. Non-strategic suppliers, on the other hand, do not work in the product's development, that is, they only participate in the supply chain 


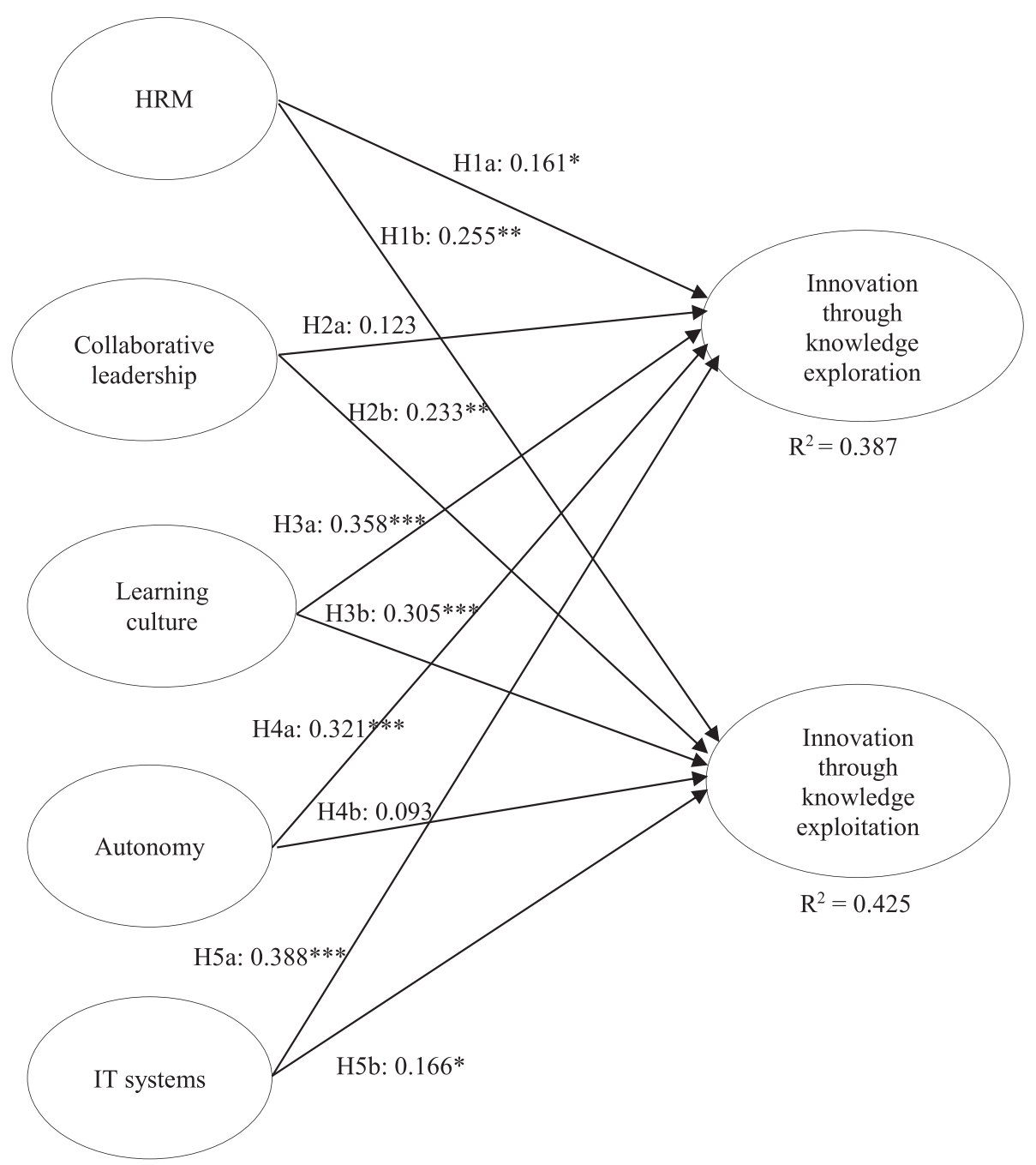

Fig. 2. Structural model testing.

Table 3

Evaluation of the structural model.

\begin{tabular}{llll}
\hline Path & Path coefficient & t-Value & Result \\
\hline H1a: HRM $\rightarrow$ exploration & $0.161^{*}$ & 1.592 & Accepted \\
H1b: HRM $\rightarrow$ exploitation & $0.255^{* *}$ & 3.586 & Accepted \\
H2a: Supportive leadership $\rightarrow$ exploration & 0.123 & 1.269 & Rejected \\
H2b: Supportive leadership $\rightarrow$ & $0.233^{* *}$ & 3.331 & Accepted \\
$\quad$ exploitation & & & \\
H3a: Learning culture $\rightarrow$ exploration & $0.358^{* * *}$ & 5.363 & Accepted \\
H3b: Learning culture $\rightarrow$ exploitation & $0.305^{* * *}$ & 4.011 & Accepted \\
H4a: Autonomy $\rightarrow$ exploration & $0.321^{* * *}$ & 4.380 & Accepted \\
H4b: Autonomy $\rightarrow$ exploitation & 0.093 & 1.391 & Rejected \\
H5a: IT $\rightarrow$ exploration & $0.388^{* * *}$ & 16.011 & Accepted \\
H5b: IT $\rightarrow$ exploitation & $0.166^{*}$ & 1.648 & Accepted \\
\hline
\end{tabular}

Note:

${ }^{*} p<0.05$.

*** $p<0.01$.

*** $p<0.001$.

(Gonzalez \& Martins, 2014). The results show that most strategic suppliers $(87.5 \%)$ are concentrated in cluster 1 ; and cluster 3 , which features lower power of innovation from knowledge exploration and exploitation, is composed of non-strategic suppliers only. It can be noted that cluster 1 is predominantly formed by large companies, both with regard to revenue $(86.7 \%$ of the companies' revenue exceeds $\mathrm{R} \$ 90$ million/year), and to the number of employees ( $60 \%$ of the companies
Table 4

The one-way ANOVA results were used to test the difference of the factors' means between the clusters.

\begin{tabular}{|c|c|c|c|c|c|c|}
\hline \multirow[t]{2}{*}{ Factor } & \multicolumn{2}{|l|}{$\begin{array}{l}\text { Between } \\
\text { groups }\end{array}$} & \multicolumn{2}{|c|}{$\begin{array}{l}\text { Within the } \\
\text { groups }\end{array}$} & \multirow[t]{2}{*}{$\mathrm{F}$} & \multirow[t]{2}{*}{ Significance } \\
\hline & $\begin{array}{l}\text { Mean } \\
\text { square }\end{array}$ & df & $\begin{array}{l}\text { Mean } \\
\text { square }\end{array}$ & df & & \\
\hline HRM & 29.303 & 2 & 0.176 & 75 & 166.496 & $0.000^{*}$ \\
\hline $\begin{array}{l}\text { Supportive } \\
\text { leadership }\end{array}$ & 44.683 & 2 & 0.221 & 75 & 202.185 & $0.000^{*}$ \\
\hline Learning culture & 30.286 & 2 & 0.191 & 75 & 158.565 & $0.000^{*}$ \\
\hline Autonomy & 54.835 & 2 & 0.188 & 75 & 291.673 & $0.000^{*}$ \\
\hline IT & 65.474 & 2 & 0.236 & 75 & 277.431 & $0.000^{*}$ \\
\hline $\begin{array}{l}\text { Innovation through } \\
\text { exploration }\end{array}$ & 66.823 & 2 & 0.208 & 75 & 321.266 & $0.000^{*}$ \\
\hline $\begin{array}{l}\text { Innovation through } \\
\text { exploitation }\end{array}$ & 63.004 & 2 & 0.215 & 75 & 293.044 & $0.000^{*}$ \\
\hline
\end{tabular}

Note: * indicates difference in the means of the three clusters, according to oneway ANOVA; df. - degree of freedom.

have $>1500$ employees). Clusters 2 and 3 are formed mainly by companies with revenue between $\mathrm{R} \$ 16$ million and $\mathrm{R} \$ 90$ million, $53.8 \%$ and $63.6 \%$, respectively, and with $<1500$ employees, $80.8 \%$ and $72.8 \%$, respectively. In relation to the companies' market time, cluster 1 is predominantly formed by companies that have been over 40 years in the market (53.3\%), and cluster 2 by companies that have 
Table 5

Clusters' centroids in relation to the seven factors studied.

\begin{tabular}{llll}
\hline Factor & Cluster 1 & Cluster 2 & Cluster 3 \\
\cline { 2 - 4 } & $\begin{array}{l}\text { Innovative } \\
\text { companies }\end{array}$ & $\begin{array}{l}\text { Exploitative } \\
\text { companies }\end{array}$ & $\begin{array}{l}\text { Passive } \\
\text { companies }\end{array}$ \\
\hline HRM & 4.288 & 4.236 & 2.755 \\
Supportive leadership & 4.093 & 4.235 & 3.526 \\
Learning culture & 5.133 & 4.888 & 3.331 \\
Autonomy & 4.671 & 3.454 & 2.863 \\
IT & 4.765 & 3.843 & 3.228 \\
Innovation through & 4.566 & 3.244 & 2.341 \\
$\quad$ exploration & & 4.956 & 3.125 \\
Innovation through & 5.021 & 52 & 11 \\
$\quad$ exploitation & & & \\
No. of cases & 15 & & \\
\hline
\end{tabular}

Table 6

Descriptive characteristics of the clusters.

\begin{tabular}{|c|c|c|c|c|}
\hline & $\mathrm{N}$ & Cluster 1 & Cluster 2 & Cluster 3 \\
\hline \multicolumn{5}{|l|}{ Type of supplier } \\
\hline Strategic supplier & 24 & $21(46.7 \%)$ & $3(1.9 \%)$ & $0(0.0 \%)$ \\
\hline Non-strategic supplier & 210 & $24(53.3 \%)$ & $153(98.1 \%)$ & $33(100.0 \%)$ \\
\hline \multicolumn{5}{|l|}{ Headquarters location } \\
\hline Asia & 6 & $3(6.7 \%)$ & $3(1.9 \%)$ & $0(00.0 \%)$ \\
\hline Brazil & 96 & $9(20.0 \%)$ & $60(38.5 \%)$ & $27(81.8 \%)$ \\
\hline USA & 48 & $12(26.7 \%)$ & $33(21.1 \%)$ & $3(9.1 \%)$ \\
\hline Europe & 84 & $21(46.6 \%)$ & $60(38.5 \%)$ & $3(9.1 \%)$ \\
\hline \multicolumn{5}{|c|}{ Company's annual revenue (in millions of Brazilian Reals (BRL)) } \\
\hline Over 300 & 54 & $30(66.7 \%)$ & $18(11.6 \%)$ & $6(18.2 \%)$ \\
\hline Between 90 and 300 & 69 & $9(20.0 \%)$ & $54(34.6 \%)$ & $6(18.2 \%)$ \\
\hline Between 16 and 90 & 111 & $6(13.3 \%)$ & $84(53.8 \%)$ & $21(63.6 \%)$ \\
\hline \multicolumn{5}{|l|}{ Number of employees } \\
\hline Over 4999 & 30 & $18(40.0 \%)$ & $6(3.8 \%)$ & $6(18.2 \%)$ \\
\hline Between 1500 and 4999 & 36 & $9(20.0 \%)$ & $24(15.4 \%)$ & $3(9.1 \%)$ \\
\hline Between 500 and 1499 & 72 & $9(20.0 \%)$ & $60(38.5 \%)$ & $3(9.1 \%)$ \\
\hline Between 100 and 499 & 96 & $9(20.0 \%)$ & $66(42.3 \%)$ & $21(63.6 \%)$ \\
\hline \multicolumn{5}{|c|}{ Company's time of operation (years) } \\
\hline Over 40 & 75 & $24(53.3 \%)$ & $45(28.9 \%)$ & $6(18.2 \%)$ \\
\hline Between 20 and 40 & 63 & $12(26.7 \%)$ & $48(30.8 \%)$ & $3(9.1 \%)$ \\
\hline Between 10 and 20 & 78 & $6(13.3 \%)$ & $57(36.5 \%)$ & $15(45.5 \%)$ \\
\hline Between 5 and 10 & 18 & $3(6.7 \%)$ & $6(3.8 \%)$ & $9(27.3 \%)$ \\
\hline
\end{tabular}

been between 10 and 20 years in the market (36.5\%). It stands out that $50 \%$ of companies with lower market time (between 5 and 10 years) belong to cluster 3 .

\section{Discussion}

This study analyzed the following issue: how do the contextual factors of the organization relate to innovation from knowledge exploration and exploitation? The research model is based on the three constructs associated with the organizational context, also called success critical factors of KM: people, organization and IT (Gold et al., 2001; Gonzalez \& Martins, 2014). The research encompassed a total of 234 companies of the automotive industry and the model explains $38.7 \%$ and $42.5 \%$ of the variance of innovation through knowledge exploitation and exploration, respectively.

This research provides new evidence that HRM, leadership, culture, autonomy and IT systems have influence over the processes of innovation from the knowledge exploration or exploitation. In line with previous studies, this article offers more evidence that organizational conditions associated with the aforementioned factors interfere in organizational innovation (Donate \& Guadamillas, 2011; Ho, 2009). However, few studies evaluate the relationship between these organizational conditions and procedures of knowledge exploration and exploitation. Another contribution this research offers is the mapping of clusters in relation to the development of these contextual factors.

This study is based on previous work which state that the practices of knowledge exploration and exploitation are guided by organizational values focused on the management and development of human resources (Bontis \& Serenko, 2007; Figueiredo et al., 2016; Zangiski et al., 2013), supportive leadership practices (Analoui et al., 2012; Politis, 2001), learning culture (Donate \& Guadamillas, 2011; Ma et al., 2014), autonomy (Ho et al., 2014; Lee \& Choi, 2003) and IT systems (Bansler \& Havn, 2004; Xue et al., 2011). Other studies also claim that organizational factors are essential elements to facilitate the implementation of KM strategies (Donate \& Guadamillas, 2011; Gonzalez \& Martins, 2014; Zack et al., 2009). Another important assumption of this work concerns the results of Gupta et al. (2006), Crossan and Bedrow (2003), Levinthal and March (1993) and March (1991) who conceptualize organizational innovation as a mix between the processes of knowledge exploration and exploitation. March (1991) considers that exploitation consists of the refinement and extension of the organization's competences, paradigms and technologies, and Gupta et al. (2006) discuss this further in stating that both knowledge exploration and exploitation are innovation processes, and the difference between the two is the extent or type of innovation.

In relation to the factors included in the structural model, it may be noted that learning culture is the factor with the greatest impact in relation to the processes of knowledge exploration and exploitation ( $\beta=0.358$ and $\beta=0.305$, respectively). As previous works suggest, an organizational culture with values geared towards learning and sharing of knowledge can be considered one of the main catalysts of innovation processes based on knowledge exploration and exploitation (Gold et al., 2001). The organizational culture that sustains KM is characterized by a state of mutual trust and identification of individuals in relation to the working groups and the organization itself, sustaining the flow and, consequently, the transformation of knowledge. These results are also in line with Corfield and Paton (2016) and Lin (2014) who state that the presence of assumptions of a learning culture eliminates focuses of resistance to change and to the implementation of KM initiatives itself. Learning-oriented culture, therefore, creates an environment that stimulates the proposition and sharing of ideas, leveraging new innovation opportunities.

With the exception of the learning culture factor, other factors showed bigger differences in what concerns the levels of significance or acceptance of the hypothesis test when compared to the processes of knowledge exploration and exploitation. HRM was significantly and positively related to the exploration and exploitation processes ( $\beta=0.161$ and $\beta=0.255$, respectively). This result shows that HRM practices are more positively related to knowledge exploitation than to knowledge exploration. This result can be explained by the fact that for an organization to reach a higher level of innovation through the knowledge exploration, it needs to develop HRM practices that are different from those used in relation to exploitation, such as training and development of problem-solving methods and incentives and awards for work in groups, targeting incremental improvements. The knowledge exploration is more dependent on HRM actions aimed at employee exchanges between units that are internal and external to the organization (Bontis \& Serenko, 2007), formation of communities of practices (Zárraga \& Bonache, 2005) and training courses on new technologies for qualifying employees (Lefebvre, Sorenson, Henchion, \& Gellynck, 2016).

Hypothesis H2, which verified the impact of supportive leadership on the processes of exploration and exploitation, was accepted only for the knowledge exploitation $(\beta=0.233)$, and, separately, hypothesis $\mathrm{H} 3$, which assessed the relationship between autonomy and the processes of knowledge exploration and exploitation, was accepted only for exploration $(\beta=0.321)$. These results fill gaps from previous studies that assess the impact of leadership and autonomy on innovation, KM or use of knowledge without distinguishing the isolated impact on the processes of knowledge exploration and exploitation. von Krogh, 
Nonaka, and Rechsteiner (2011) state that leaders assume a key role in establishing policies and organizational infrastructure that enhance and facilitate the flow of knowledge and KM. Leaders are also responsible for implementing practices of HRM focused on retention and dissemination of lessons learned and better practices (Bollinger \& Smith, 2001). Davenport et al. (1998) also highlight the role of leadership in the development of a culture that encourages the sharing of knowledge among employees. The contributions of these three studies, geared towards the retention and dissemination of lessons learned, the encouraging to the flow of knowledge between employees and development of infrastructure for $\mathrm{KM}$, show that supportive leadership practices support effectively the process of knowledge exploitation, since these practices are focused on the refinement and improvement of the same primary knowledge base, while exploration requires actions geared towards research, discovery and development of new knowledge (March, 1991).

These considerations oppose the result verified for autonomy. As exploration requires the breaking of paradigms and researching of new technologies, the autonomy for employees to implement and develop new knowledge becomes essential in the process of knowledge exploitation. Separately, the exploitation of the same primary knowledge base does not require a high level of autonomy, because the changes in processes and products are not radical.

Finally, the structural model pointed out that both knowledge exploration $(\beta=0.388)$ and exploitation $(\beta=0.166)$ were significantly and positively related to the use of IT systems. The effective use of IT systems supports the process of retention and coding of explicit knowledge, facilitating its dissemination and exploitation. IT systems also allow individuals of different functional areas and organizational units to be integrated and connected, facilitating the exchange of knowledge and information. In addition, IT also supports knowledge exploration through the formation of practice communities, which connect individuals from different areas of the organization with research centers, universities, suppliers, and clients (Zárraga \& Bonache, 2005). In this way, the use of IT acts as a facilitator in the processes of formalization, which is positively related to knowledge exploitation, and also to functional integration and to the integration between teams and functional areas, that have the most significant impact concerning knowledge exploration.

Through the cluster analysis it was possible to classify the suppliers of the automotive industry into three groups: innovative, exploitative and passive. The first group, innovative, is formed by $19.23 \%$ of the surveyed companies, totaling $87.5 \%$ of the strategic suppliers, being formed predominantly by large companies with more time in the market. In this group, the high levels in both factors of innovation through knowledge exploration and exploitation, associated with autonomy, learning culture and use of IT systems, stand out.

The second group consists of $66.67 \%$ of the surveyed companies, being formed predominantly by non-strategic suppliers (98.1\%), most being companies with revenues, number of employees and market time at intermediate levels, when compared to the two other groups. In this group, the high average scores of the innovation through exploitation, supportive leadership and learning culture factors and, on the other hand, the low average scores of the innovation through exploration and autonomy factors stand out. These results show that this group uses the same primary knowledge base in order to refine the processes and technologies already adopted. For being mostly non-strategic suppliers, these companies do not seek radical innovation of their products and processes.

Analyzing the main differences between groups 1 and 2, it may be noted that the high level of innovation through exploration and exploitation, presented by group 1, is accompanied by high levels of autonomy, learning culture and use of IT systems. On the other hand, the high exploitation level, presented by the companies of group 1, is accompanied by learning culture and supportive leadership. In this way, it can be seen that the higher level of exploitation of knowledge achieved by the companies of group 1 requires greater autonomy on the part of employees so they may work in the research, discovery and development of new products, processes and technologies. On the other hand, the high level of knowledge exploitation, in isolation, as may be noted in group 2, occurs with a lesser degree of autonomy when compared to group 1, and with active and supportive involvement on the part of managers, that is, they are responsible for guiding the actions of improvement and refinement of the processes' efficiency, which require knowledge exploitation.

The third group is made up of $14.10 \%$ of the surveyed companies, being composed entirely by non-strategic suppliers with revenues, number of employees and market time relatively lower than the other two groups identified. Companies in this group exhibit average scores lower than those of the other two groups in relation to all contextual factors surveyed. Companies of this group exhibit a low level of exploration of new knowledge and of exploitation of their primary knowledge base, showing that these companies are just followers and supporters of the companies of the first two groups, with regard to innovation.

This study is a pioneer in classifying the companies as to the exploration and exploitation of innovation knowledge, associating these levels of innovation to the development of contextual factors of the organization. Similar works, such as that by Joshi, Chawla, and Farooquie (2014), use contextual factors in order to analyze the planning and implementation of KM. The work of Joshi et al. (2014) discusses four factors also addressed in this study: leadership, technology, culture and structure, in what concerns autonomy. Liu and Deng (2015) classify businesses in relation to the ability to perform KM, distinguishing them with regard to the processes of acquisition, conversion, application and protection of knowledge. Lin (2014) also uses the method of cluster analysis in order to assess the stage of evolution of KM. However, it may be noted that the focus of these three works is the KM process. In the literature, works which classify companies according to the processes of knowledge exploration and exploitation, along with the contextual factors of the organization, have not been found.

\section{Conclusion}

This study presents empirical evidence of the impact of five contextual factors of the organization (HRM, supportive leadership, learning culture, autonomy and IT systems) in relation to the practice of innovation through knowledge exploration and exploitation. The results of the structural model show that exploration and knowledge is more impacted by the use of IT systems, autonomy and learning culture. Exploitation of knowledge, on the other hand, is more related to the learning culture and supportive leadership. HRM showed intermediate levels of impact in relation to both processes. It also stands out that supportive leadership does not have influence over the knowledge exploration and autonomy has no impact on the knowledge exploitation.

The cluster analysis pointed out the existence of three distinct groups in what concerns the practice of innovation through knowledge exploration and exploitation and development of contextual factors. The former, called "innovative companies," formed predominantly by strategic suppliers of the automotive industry, offers high levels of knowledge exploration and exploitation; the second group, named "exploitative companies," is predominantly made up of non-strategic suppliers with a focus on innovation through knowledge exploitation. And the third group, called "passive companies," is formed exclusively by non-strategic suppliers and offers relatively low levels for all factors surveyed.

In relation to the development of the contextual factors within the groups, the high level of learning culture and use of IT systems by the group "innovative companies" stands out. In the group "exploitative companies," the factors learning culture and supportive leadership stand out. In this way, it can be concluded that the most innovative companies are less dependent on supervision and guidance on the part 
of leaders, when compared to companies that only exploit. This is justified by the fact exploitative companies are more active in the revision, refinement and efficiency improvement of processes and products with the support and guidance of managers and supervisors, using the same primary knowledge base, in an environment that encourages the sharing of knowledge between individuals. Innovation, on the other hand, in addition to learning culture, is more dependent on a context that gives autonomy to the process of research, discovery and development of new technologies and knowledge. In addition, innovative companies also depend on the availability of IT systems, which allow employees to participate in forums and communities of practice with individuals from other units of the company, or other institutions such as partners, suppliers, customers and universities, in order to leverage the process of exploration of new knowledge.

Although this study presents satisfactory results, it is possible to identify some limitations that need to be evaluated in future studies. Firstly, although a substantial portion of the variance relative to knowledge exploration and exploitation can be explained by the model, the explanatory power can be improved. Other variables, in particular those associated with the organizational sphere, such as leadership style, management support, organizational atmosphere, awarding, may be included in the model.

Secondly, although the research instrument has undergone a pilot test, the data collection method can generate errors, since it uses interviews carried out without the presence of the researcher. Thirdly, our conceptual model does not consider the specificity, complexity, and characteristics of the companies. To overcome this limitation, future research may consider organizational characteristics such as size, capital type, location etc. Fourthly, using the automotive industry as object of study may limit the generalization of the results to other contexts. Further study is required to assess to what extent the results of this study are applicable to various industries.

\section{Acknowledgments}

The author thanks National Council for Scientific and Technological Development - CNPq (Process number: 445205/2014-8) and São Paulo Research Foundation - FAPESP (2016/24401-2 and 2016/18414-4) for the financial support, and Espaço da Escrita - Unicamp for having translated the manuscript into English.

\section{Appendix A. Measurement items}

\section{A.1. Human resource management (HRM)}

HRM1. The company's selection process considers the alignment between the skills and knowledge of the employee and the company's core competencies.

HRM2. There is a structured and systematic process for evaluating the skills of employees.

HRM3. The company provides training to employees in order to solve the shortcomings noted in their evaluation.

HRM4. The company offers possibility of professional growth, based on the employee's performance.

HRM5. Employees are rewarded and recognized for achievements.

\section{A.2. Supportive leadership (SL)}

SL1. Leadership creates an environment that promotes teamwork.

SL2. Managers take on the role of knowledge leaders, guiding their subordinates in relation to better practices that promote the meeting of goals and objectives.

SL3. Managers act as advisers and control mechanisms are used to evaluate the achievement of goals and objectives.

\section{A.3. Learning culture (LC)}

LC1. Employees share ideas, knowledge and skills related to processes which they are part of.

LC2. During group activities, employees are encouraged to share experiences and lessons learned.

LC3. Employees are encouraged to explore new opportunities.

LC4 The company interprets any errors committed by employees in improvement activities as part of the learning process.

\section{A.4. Autonomy (Aut)}

Aut1. The employees of the working groups have the capacity to self-manage, i.e., self-organization capacity.

Aut2. Employees have the power to make decisions related to daily work, problem solving and improvement initiatives.

Aut3. Employees participate in the process of planning and defining of goals and objectives pertaining to their field of operation.

\section{A.5. IT systems (IT)}

IT1. IT systems facilitate the distribution and retention of the knowledge acquired.

IT2. When an improvement is planned by a team, individuals seek information in the informational systems.

IT3. Employees use IT systems in order to communicate with other individuals from within and outside the organization in order to share knowledge and ideas.

\section{A.6. Knowledge exploration practices (Expl)}

Expl1. Employees use their knowledge and skills in incremental improvement activities and problem-solving.

Expl2. Employees use their knowledge and skills in order to solve problems.

Expl3. The company presents a program of ideas and suggestions of employees to promote incremental improvements in processes.

\section{A.7. Knowledge exploitation practices (Expt)}

Expt1. The company can easily access new technologies through, for example, partnerships with other companies, universities, consulting offices etc.

Expt2. The company invests in the research and development of new technologies to improve or develop products/processes.

Expt3. The company can easily introduce new technologies into its processes or products without any great resistance to change.

\section{References}

Analoui, B. D., Doloriert, C. H., \& Sambrook, S. (2012). Leadership and knowledge management in UK ICT organisations. Journal of Management Development, 32(1), $4-17$.

APQC (2003). Knowledge management: Executive summary. Consortium benchmarking study best-practice reportAmerican Productivity \& Quality Center. (Retrieved from) www.apqc.org, Accessed date: 10 October 2016.

Bansler, J. P., \& Havn, E. (2004). Exploring the role of network effects in IT implementation: The case of knowledge repositories. Information Technology \& People, 17(3), 268-285.

Blanco, A. F., Echaluce, M. L. S., \& Peñalvo, F. G. (2015). Epistemological and ontological spirals: From individual experience in educational innovation to the organisational knowledge in the university sector. Program, 49(3), 266-288.

Bollinger, A. S., \& Smith, R. D. (2001). Managing organizational knowledge as a strategic asset. Journal of Knowledge Management, 5(1), 8-18.

Bontis, N., \& Serenko, A. (2007). The moderating role of human capital management practices on employee capabilities. Journal of Knowledge Management, 11(3), 31-51.

Chen, C. J., \& Huang, J. W. (2007). How organizational climate and structure affect knowledge management: The social interaction perspective. International Journal of Information Management, 27(2), 104-118.

Chen, C. J., Huang, J. W., \& Siao, Y. C. (2010). Knowledge management and 
innovativeness: The role of organizational climate and structure. International Journal of Manpower, 31(8), 48-70.

Chourides, P., Longbottom, D., \& Murphy, W. (2003). Excellence in knowledge management: An empirical study to identify critical factors and performance measures. Measuring Business Excellence, 7(2), 29-45.

Corfield, A., \& Paton, R. (2016). Investigating knowledge management: Can KM really change organisational culture? Journal of Knowledge Management, 20(1), 88-103.

Crossan, M., \& Bedrow, I. (2003). Organizational learning and strategic renewal. Strategic Management Journal, 24, 1087-1105.

Davenport, T. H., De Long, D. W., \& Beers, M. C. (1998). Successful knowledge management projects. Sloan Management Review, 39(2), 43-57.

Dominguez, A. (2011). The impact of human resource disclosure on corporate image. Journal of Human Resource Costing \& Accounting, 15(4), 279-298.

Donate, M. J., \& Guadamillas, F. (2011). Organizational factors to support knowledge management and innovation. Journal of Knowledge Management, 15(6), 890-914.

Eisenhardt, K. M., \& Martin, J. A. (2000). Dynamic capabilities: What are they? Strategic Management Journal, 21(10), 1105-1121.

Figueiredo, E., Pais, L., Monteiro, S., \& Mónico, L. (2016). Human resource management impact on knowledge management: Evidence from the Portuguese banking sector. Journal of Service Theory and Practice, 26(4), 497-528.

Ganzaroli, A., Noni, I., Orsi, L., \& Belussi, F. (2016). The combined effect of technological relatedness and knowledge utilization on explorative and exploitative invention performance post-M \& A. European Journal of Innovation Management, 19(2), 167-188.

Gold, A. H., Malhotra, A., \& Segars, A. H. (2001). Knowledge management: An organizational capabilities perspective. Journal of Management Information Systems, 18(1), 184-214.

Gonzalez, R. V. D. (2017). Knowlede exploration and exploitation in team context. Total Quality Management and Business Excellence. http://dx.doi.org/10.1080/14783363. 2017.1400377.

Gonzalez, R. V. D., \& Martins, M. F. (2014). Mapping the organizational factors that support knowledge management in the Brazilian automotive industry. Journal of Knowledge Management, 18(1), 611-630.

Gonzalez, R. V. D., Martins, M. F., \& Toledo, J. C. (2014). Managing knowledge in a service provider: A network structure-based model. Journal of Knowledge Management 18(3), 611-630.

Gonzalez, R. V. D., \& Melo, T. M. (2017). Linkage between dynamics capability and knowledge management factors: A structural equation model. Management Decision, 55(10), 2256-2276.

Grant, R. M. (1996). Toward a knowledge-based theory of the firm. Strategic Management Journal, 17, 109-122.

Gupta, A. K., Smith, K. G., \& Shalley, C. E. (2006). The interplay between exploration and exploitation. Academy of Management Journal, 49(4), 93-706.

Hair, J. F., Hult, G. T. M., Ringle, C., \& Sarstedt, M. (2013). A primer on partial least squares structural equation modeling (PLS-SEM). London: Sage Publications Ltd2013.

He, Z. L., \& Wong, P. K. (2004). Exploration vs. Exploitation: An empirical test of the ambidexterity hypothesis. Organization Science, 15(4), 481-494.

Heisig, P. (2009). Harmonisation of knowledge management: Comparing $160 \mathrm{KM}$ frameworks around the globe. Journal of Knowledge Management, 13(4), 4-31.

Hill, S. A., \& Birkinshaw, J. (2014). Ambidexterity and survival in corporate venture units. Journal of Management, 40(7), 1899-1931.

Ho, C. F., Hsieh, P. H., \& Hung, W. H. (2014). Enablers and processes for effective knowledge management. Industrial Management \& Data Systems, 114(5), 734-754.

Ho, C. T. (2009). The relationship between knowledge management enablers and performance. Industrial Management \& Data Systems, 109, 98-117.

Holmqvist, M. (2004). Experiential learning processes of exploration and exploitation within and between organizations: An empirical study of product development. Organization Science, 15(1), 70-81.

Islam, T., Khan, S. U. R., Ahmad, U. N. B. U., Ali, G., \& Ahmed, I. (2014). Organizational learning culture and psychological empowerment as antecedents of employees' job related attitudes: A mediation model. Journal of Asia Business Studies, 8(3), 249-263.

Jones, A. B., \& Knoppen, D. (2018). The role of strategic purchasing in dynamic capability development and deployment: A contingency perspective. International Journal of Operations \& Production Management, 38(2), 446-473.

Joshi, H., Chawla, D., \& Farooquie, J. A. (2014). Segmenting knowledge management (KM) practitioners and its relationship to performance variation - Some empirical evidence. Journal of Knowledge Management, 18(3), 469-493.

Kane, G. C., \& Alavi, M. (2007). Information technology and organizational learning: An investigation of exploration and explotation process. Organization Science, 18(5), 796-812.

Kogut, B., \& Zander, U. (1992). Knowledge of the firm, combinative capabilities and replication of technology. Organization Science, 3(3), 383-397.

Lakshman, C. (2007). Organizational knowledge leadership: A grounded theory approach. Leadership and Organization Development Journal, 28(1), 51-75.

Lee, H., \& Choi, B. (2003). Knowledge management enablers, processes, and organizational performance: An integrative view and empirical examination. Journal of Management Information Systems, 20(1), 179-228.

Lee, P. K. C., To, W. M., \& Ty, B. T. W. (2013). Team attributes and performance of operational service teams: An empirical taxonomy development. International Journal of Production Economics, 142, 51-60.

Lee, S. U., Park, G., \& Kang, J. (2018). The double-edged effects of the corporate venture capital unit's structural autonomy on corporate investors' explorative and exploitative innovation. Journal of Business Research, 88, 141-149.

Lefebvre, V. M., Sorenson, D., Henchion, M., \& Gellynck, X. (2016). Social capital and knowledge sharing performance of learning networks. International Journal of Information Management, 36, 570-579.

Levinthal, D. A., \& March, J. G. (1993). The myopia of learning. Strategic Management Journal, 14, 95-112.

Li, W. (2010). Virtual knowledge sharing in a cross-cultural context. Journal of Knowledge Management, 14(1), 38-50.

Lin, H. F. (2007). A stage model of knowledge management: An empirical investigation of process and effectiveness. Journal of Information Science, 33(6), 643-659.

Lin, H. F. (2014). Contextual factors affecting knowledge management diffusion in SMEs. Industrial Management \& Data Systems, 114(9), 1415-1437.

Liu, S., \& Deng, Z. (2015). Understanding knowledge management capability in business process outsourcing: A cluster analysis. Management Decision, 53(1), 124-138.

Ma, Z., Huang, Y., Wu, J., Dong, W., \& Qi, L. (2014). What matters for knowledge sharing in collectivistic cultures? Empirical evidence from China. Journal of Knowledge Management, 18(5), 1004-1019.

March, J. G. (1991). Exploration and exploitation in organizational learning. Organization Science, 20(1), 71-87.

Marouf, L. (2016). The role of knowledge sharing culture in business performance. VINE Journal of Information and Knowledge Management Systems, 46(2), 154-174.

Martins, E. C., \& Meyer, H. W. J. (2012). Organizational and behavioral factors that in fluence knowledge retention. Journal of Knowledge Management, 16(1), 77-96.

Mohamed, M., Stankosky, M., \& Murray, A. (2006). Knowledge management and information technology: Can they work in perfect harmony? Journal of Knowledge Management, 10(3), 103-116.

Naqshbandi, M. M., \& Tabche, I. (2018). The interplay of leadership, absorptive capacity, and organizational learning culture in open innovation: Testing a moderated mediation model. Technological Forecasting and Social Change. http://dx.doi.org/10.1016/ j.techfore.2018.03.017.

Park, S., Stylianou, A., Subramaniam, C., \& Niu, Y. (2015). Information technology and interorganizational learning: An investigation of knowledge exploration and exploitation processes. Information Management, 52, 998-1011.

Patterson, W., \& Ambrosini, V. (2015). Configuring absorptive capacity as a key process for research intensive firms. Technovation, 36-37, 77-89.

Politis, J. D. (2001). The relationship of various leadership styles to knowledge management. Leadership and Organization Development Journal, 22(8), 354-364.

Razouk, A., Bayad, M., \& Wannenmacher, D. (2009). Strategic HRM and tacit knowledge transfer: A case study. Human Systems Management, 28(1/2), 77-82.

Torugsa, N. A., \& O'Donohue, W. (2016). Progress in innovation and knowledge management research: From incremental to transformative innovation. Journal of Business Research, 69, 1610-1614.

Van Dijk, A., Hendriks, P., \& Romo-Leroux, I. (2016). Knowledge sharing and social capital in globally distributed execution. Journal of Knowledge Management, 20(2), 327-343.

von Krogh, G., Nonaka, I., \& Rechsteiner, L. (2011). Leadership in organizational knowledge creation. A review and framework. Journal of Knowledge Management Studies, 49(1), 240-277.

White, G. R. T., \& Cicmil, S. (2016). Knowledge acquisition through process mapping: Factors affecting the performance of work-based activity. International Journal of Productivity and Performance Management, 65(3), 302-323.

Xue, Y., Bradley, J., \& Liang, H. (2011). Team climate, empowering leadership, and knowledge sharing. Journal of Knowledge Management, 15(2), 299-312.

Zack, M., McKeen, J., \& Singh, S. (2009). Knowledge management and organizational performance: An exploratory survey. Journal of Knowledge Management, 13(6), 392-409.

Zangiski, M. A. S. G., Lima, E. P., \& Costa, S. E. G. (2013). Organizational competence building and development: Contributions to operations management. International Journal of Production Economics, 144(1), 76-89.

Zárraga, C., \& Bonache, J. (2005). The impact of team atmosphere on knowledge outcomes in self-managed teams. Organization Studies, 26(5), 661-681.

Zheng, W., Yang, B., \& McLean, G. N. (2010). Linking organizational culture, structure, strategy and organizational effectiveness: Mediating role of knowledge management. Journal of Business Research, 63, 763-771.

Rodrigo Valio Dominguez Gonzalez has worked with research in production en gineering since 2006 and has worked in the School of Applied Science of the University of Campinas, Limeira, Brazil, since 2012 as professor and researcher. He is M.Sc. and PhD in Production Engineering from São Carlos Federal University in 2006 and 2011 respectively. Most of his research is connected with the study of Knowledge Management, Quality Management, Organizational Learning and Continuous Improvement.

Tatiana Massaroli de Melo has worked with research in economics since 2006 and has worked in the Department of Economics of the Paulista State University Julio de Mesquita Filho (UNESP), Araraquara, Brazil, since 2013 as professor and researcher. She is M.Sc. in Economics from Catholic Pontifical University in 2006 and PhD in Industrial Economic from the Federal University of Rio de Janeiro in 2011. Most of his research is connected with the study of Industrial Economics, Innovation and Strategy and Knowledge Management. 